\title{
Moral Rationalism and Demandingness in Kant: A Response to van Ackeren and Sticker
}

Because my time and competence are limited, I shall avoid exegetical discussion of Kant and restrict myself to discussion of some of the apparent implications of the views attributed to Kant by van Ackeren and Sticker (AS) in their insightful and suggestive paper.

According to AS, Kant accepts moral rationalism (MR), believing that it is always rational to do what morality demands (and, one presumes, never rational not to do what morality demands). Sometimes, obeying morality is to one's advantage, or has no implications for one's own well-being; at other times, it is a cost to one's well-being, and it is here that the problem of demandingness arises.

AS helpfully distinguish two conceptions of the defeat of non-moral by moral reasons. On the first view, moral reasons override non-moral reasons; on the second, moral reasons silence non-moral reasons. AS attribute the silencing conception to Kant. What is meant by silencing? AS elucidate it in terms of undermining, undercutting, bracketing, or excluding (p. 5). This elucidation leaves it open whether we are to understand silencing in terms of deliberation or of normativity. Consider a case in which morality requires me to refrain from eating another slice of delicious cake because it will deprive others of their fair share. On the deliberative interpretation of silencing, the virtuous person will not see the pleasure she would gain from eating the cake as a reason for so doing. This is quite consistent with its being the case that this pleasure still provides a reason. On the normative interpretation, if eating the cake would be vicious, there is no reason to eat it. That may be because vicious pleasure is not worth having; it may even be, as Aristotle might claim, that the 'pleasure' a vicious person might claim she experiences in eating the cake is not in fact pleasure at all. According to AS (p. 6), Kant accepts normative silencing, and this explains why reference to such reasons will not feature in properly rational deliberation in cases of conflict (p. 6). Indeed, it is hard to see how on this view there can be any conflict between moral and non-moral reasons. Moral reasons function like a superpower which blows any opposing country out of existence at the very moment even the smallest conflict is about to begin. This metaphor helps us see how Kant is not denying the force of non-moral reasons entirely. He holds a version of the dualism of practical reason, according to which there are non-moral reasons which do not conflict with moral reasons. ${ }^{1}$

\footnotetext{
${ }^{1}$ At a later point in their paper (p. 11), AS seem to interpret Kant as holding a restricted version of what we might call 'moral monism', according to which, when duty requires some action $A$, other reasons for $A$-ing fall away: 'whatever non-moral reasons there were to act on one's inclinations before the conflict, these are not to be weighed against duty since they do not count as reasons anymore when they would conflict with duty' (p. 11). Such monism is restricted in the sense that it will allow for genuine non-moral reasons in cases where no moral requirement is in play. So, given
} 
It may be that I am misunderstanding AS here, however, for later (p. 9) they appear to allow that Raz's notion of exclusionary reasons is in line with Kant's view. Exclusionary reasons 'exclude acting for another reason which is a valid reason for acting', according to Raz, and AS comment:

This relation between reasons is what we find in Kant: In cases of conflict between duty and one's pursuit of happiness, duty becomes an exclusionary reason with regard to all other considerations that otherwise constitute valid reasons for actions.

I suspect, however, that AS's interpretation of Raz may be in line with the normative view of silencing: consider their introduction of 'otherwise' into the account. ${ }^{2}$ We might, that is to say, insert 'would' before 'otherwise' without change

a choice between two actions, one of which will make me happy and the other of which will not, if all else is equal I have a non-moral reason to choose the former. But we need to ask why Kant might feel the need for restricted moral monism. AS suggest that it is a matter of correct moral motivation. Kant would have doubts, they suggest, about someone who said that they paid back a debt because (a) it was her duty and (b) it enabled her to avoid punishment or a bad reputation. But this again seems to blur the line between deliberation and normativity. On a more plausible view, the self-interested non-moral reasons to $A$ remain even when $A$-ing is required by morality, but the virtuous agent will not take them into account or be motivated by them.

${ }^{2}$ Note also what AS say when explaining the differences between the accounts of silencing in McDowell and Kant (pp. 10-11). Kant allows for psychological conflict, since the objects of our inclinations remain attractive to rational finite agents - even if, we may assume, they are virtuous (Kant's virtuous agents, that is to say, are moral heroes, and have to be, since there would be nothing of moral worth in the actions of saints (who are truly 'non-moral') who have no inclinations to overcome). But despite the psychological conflict, this 'is no longer a case of conflicting reasons that need to be weighed against each other' (because, that is to say, there is no longer any conflict). The virtuous agent will feel the pull of her inclinations towards the cake, but - knowing that she has no genuine reason to eat it - will act against her inclinations and out of pure respect for the moral law. In the same way, when duty and inclination coincide, as in the case of repaying a debt discussed in the previous note, the virtuous agent's action is entirely to be explained by her acting out of respect for the moral law - even though she feels the attraction of avoiding punishment and a bad reputation. This is of course all very mysterious, but that is entirely in line with the Kantian metaphysics in the background to his ethics. Also puzzling is how, if Kant is indeed a dualist of the practical reason, there can be reasons at all in the absence of moral demands. Given that Kant tends to understand reasons in terms of what can be rationally willed, and to equate rationality and free 
of sense. In the cake case, if there were no duty not to eat another slice, the pleasantness of doing so would constitute a reason to do it. Once there is a duty, that reason disappears. It seems clear to me, however, that Raz's version of silencing is merely deliberative. Consider what he says about self-denying fasting on the same page as that quoted by AS: the very point of such a fast is that we deny ourselves something we have (not 'would have') a reason to pursue. Normative silencing can make no room for self-denial of this kind, and this is one of the various aspects of it that seem at the least somewhat surprising.

Another surprising aspect - which I believe we find in the ethics of Aristotle and some other ancient philosophers - is that, on the normative silencing view, vicious action becomes entirely irrational. Consider what Kant says about undeserved happiness (mentioned by AS on p. 9). On the standard view, the vicious or immoral agent has a reason to pursue her own happiness, because it will make her own life better, but such happiness is itself bad - it makes the world, as it were, worse. According to the normative silencing view, the vicious agent has no reason to pursue her happiness, except within the bounds of duty, because to do so would be to act inconsistently with her duty. Is her happiness nevertheless still good for her, even though she has no reason to pursue it? On the Aristotelian view, it is not, since true happiness consists only in the exercise of the virtues. Indeed, she has a positive reason to avoid such pursuit, since pursuing pleasure (or apparent pleasure) will actually make her life worse. The Kantian view, according to AS as I understand them, is that happiness consists in pleasure, and to that extent the vicious person will make her life better for herself by pursuing it even when duty requires her not to (if it were not good for her, it is not clear why anyone would want to say it was 'undeserved'). But she has no reason to do so. Here perhaps we see another example of the extreme impartiality for which Kant and Kantians have been criticized for the past two centuries.

In their discussion of demandingness in Kant, AS focus on imperfect duties, duties to promote obligatory ends such as the happiness of others. They reject Timmermann's interpretation of Kant, according to which, on any occasion on which

agency with acting out of duty, there must be a case for understanding him as an unrestricted moral monist. This would make his view even more remarkable than that of Aristotle. According to Aristotle, I never have reason to do anything except exercise the virtues; but that is because such exercise will maximally promote my happiness. According to Kant, I have no ultimate reason, ever, to promote my own happiness. Rather, my only ultimate reason is to act out of a sense of duty. On this view, the issue of demandingness, arising out of a conflict between the demands of morality and the agent's happiness, does not disappear, but it becomes entirely deracinated and insignificant. What is needed for a genuine problem of demandingness is a conflict of reasons, not a 'conflict' (if the term is even appropriate here) between a single reason and a good which there is no reason to pursue. 
we can benefit others or perfect ourselves, we are required to do so, unless doing so would be in violation of a perfect duty. This interpretation does make Kant's view extremely demanding, though as far as I can see it may still allow for some degree of latitude to the agent in deciding whom to benefit. Imagine a world in which my wellbeing is at level 10, and there are two other individuals $P$ and $Q$, whose well-being is at level 6 and level 4 respectively. I have two options: either to bring $P$ up to level 8 , or $Q$ up to level 7. Either option will bring my own well-being down to level 8. If all else is equal, it seems that Kant, on Timmermann's interpretation, will require me to make a sacrifice; but it may be up to me whether I benefit $P$ or $Q$ (I might have a whim to benefit $P$, perhaps, or wish to toss a coin between them). It remains unclear what Timmermann's Kant will say of cases in which the cost to me of benefiting $P$ is greater than that of my benefiting $Q$.

On AS's view, latitude arises also in how much is demanded of me by imperfect obligations themselves: 'the absolute rational authority of the moral law does not require that we do as much as we can' (p. 13). But this, as AS recognize, raises the question of just how much we are required to do. It would seem implausible to claim that a billionaire who gives only one cent when he is in a position to help others is doing everything morality requires of him in relation to imperfect duties. ${ }^{3}$ Imperfect duties require not just that we do something, AS conclude, but that we do something that can be reasonably construed as genuinely helping.

Note first the possibility of 'imperceptible benefits'. Consider an analogue to Derek Parfit's famous case of the 'harmless torturers', in which 1,000 beneficent billionaires each give one cent to each of 1,000 needy beneficiaries. Each beneficiary will end up in the same position as if each billionaire had each given $\$ 10$ to a different individual beneficiary.

But there is something significantly more worrying about Kant's view as so described. Not only does it seem to allow for the kind of latitude over whom to benefit described above, but it may permit agents to give priority to minor benefits to themselves over the prevention of major harms to others. For example, if I am already donating, say, $10 \%$ of my income to some effective charity, should I be permitted to spend money on non-basic foods, holidays, or even educational events for my children when very small amounts of money can prevent relatively huge amounts of suffering? It seems to me a problem for Kant's view if it includes this permission. But I also wonder whether it can, since it is hard to see how rational or reasonable beings could will as universal laws of nature maxims which would include such a permission. And the same seems to me likely to be true even if I am giving 60 or $70 \%$ of my income. The issue of demandingness in modern philosophy has arisen among philosophers who appear to believe themselves entitled to keep

\footnotetext{
${ }^{3}$ We have to assume a world different from our own, of course, since in this world billionaires always have the chance to help others, and so would end up sacrificing billions, even if in very small amounts.
} 
relatively large amounts of money while many others in the world have barely anything. The problem, it seems to me, is not so much with demandingness as with the moral compass of these philosophers.

Roger Crisp

St Anne's College, Oxford

Oxford Uehiro Centre for Practical Ethics

Centre for Moral Philosophy and Applied Ethics (IRCI), Australian Catholic University 